\title{
Catastrophic and impoverishing health expenditures and it's affecting factors among health staffs in Iran: A case study in Tehran
}

\author{
Parisa Mehdizadeh ${ }^{1}$, Hossein Daniyali ${ }^{1}$, Mohammad Meskarpour-Amiri ${ }^{1}$, Nooredin Dopeykar*2, Hadi Uzi $^{3}$
}

Received: 2 Nov 2016

\author{
Published: 11 Nov 2019
}

\section{Abstract}

Background: Despite a lot of studies carried out on catastrophic and impoverishing health expenditures, exposure to these expenditures have not been studied among health staffs and their families yet. So that our study has analyzed exposure to CHE (Catastrophic Health Expenditures) and factors affecting them among the health staffs affiliated to army medical universities in Tehran.

Methods: This study was a descriptive-analytical and cross-sectional study implemented in 2016. Among all health staffs of a university of medical sciences, the full details of 240 households (838 individuals) were collected by using a stratified random sampling method. The data gathering and analyzing process have been done based on WHO standard guideline. Finally, the odds ratio of CHE determinants is reported using logistic regression by backward elimination method and chi-square test.

Results: The results of this study showed that $7.5 \%$ (CI: 7.3-7.7) of health staff households (54 individuals) are faced with CHE. The odds of exposure to CHE for households with 3 members and less, households with lower education level and households with two or more outpatient visits were significantly more than others $(\mathrm{p}<0.05)$. Households who have used dental services during the past year were 8.77 times $(p<0.001)$ more at risk of CHE. Also, households with 3 members and less, households with lower education level and households with two or more outpatient visits were 8.59, 7.96, and 3.39 times more at risk of such payments, respectively.

Conclusion: CHE is a common financing dilemma even among health staffs. Families who have more referring to health centers and less education level and also dental service users are more at risk of exposure. Health policy-makers should pay more attention to such vulnerable and high-risk groups. Finally, our study results recommended the increase of dental insurance coverage as an effective strategy to reduce exposure to CHE.

Keywords: Catastrophic health expenditures, Impoverishing health costs, Health personnel

Conflicts of Interest: None declared

Funding: None

\section{*This work has been published under CC BY-NC-SA 1.0 license.}

Copyright $\odot$ Iran University of Medical Sciences

Cite this article as: Mehdizadeh P, Daniyali H, Meskarpour M, Dopeykar N, Uzi H. Catastrophic and impoverishing health expenditures and it's affecting factors among health staffs in Iran: A case study in Tehran. Med J Islam Repub Iran. 2019 (11 Nov);33:120. https://doi.org/10.47176/mjiri.33.120

\section{Introduction}

Although the objective of many countries is to design health financing system in a way to protect their people against Health Care Expenditure (HCE), but in developing

\section{Corresponding author: Dr Nooredin Dopeykar, n.dopeykar@gmail.com}

1. Health Management Research Center, Baqiyatallah University of Medical Sciences, Tehran, Iran

2. Research Center for Prevention of Oral and Dental Diseases, Baqiyatallah University of Medical Sciences, Tehran, Iran

3. Department of Health Economic and Management, Tehran University of Medical Science, Tehran, Iran

countries, only a few fraction of people are maintained against the financial risks of illness. This issue is due to a set of reasons, the most important of which is the lack of

\section{$\uparrow$ What is "already known" in this topic:}

Despite many studies conducted on catastrophic health expenditures in the general population, the exposure to catastrophic health expenditures has not been studied for health system's personnel and their families yet.

\section{$\rightarrow$ What this article adds:}

According to our study results, $7.5 \%$ of health staff households have exposure to catastrophic health expenditures. Also $1.67 \%$ of them were driven below the poverty line due to payment for medical expenditures. Although this ratios are lower than the reported ratios in general population, but it's still worrying. 
governments' commitment, lack of financial resources to cover the entire population and the lack of ability to manage health insurance funds (1). Despite many scientific studies conducted about the health system functions and health financing in the past decade, the policymakers' understanding of a health system with desirable features protecting households against CHE is still low, so such studies are still required in this area especially in developing countries (2).

Today, the lack of financial protection against illness is known as health systems problem or challenges. The clearest sign of this disease is that households suffer not only from the illness but also from the financial burden and the poverty arising from the illness (1). In the health economics approach, the CHE is that the health services expenditures have exceeded a certain threshold of household's ability to pay (3). As suggested by Xu et al. if the household's HCE is equal to and greater than $40 \%$ of their capacity to pay, they are considered as catastrophic. In this definition, the household's residual income after meeting basic needs is known as household's capacity to pay (2).

According to the WHO's report in 2008, about 100 million people have gone under the poverty line due to HCE all over the world (4). Moreover, the WHO report in 2006 showed that more than $50 \%$ of health expenditures in Iran financed through out-of-pocket payment $(4,5)$. However, Iran's upstream documents- including the Islamic Republic of Iran's Fifth Development Plan and the Health Map of the Islamic Republic of Iran- emphasize on decreasing out-of-pocket health expenditures and improving equity in financing of the health system.

Despite the many studies conducted on CHE in the general population, the exposure to $\mathrm{CHE}$ has not been studied for health system's personnel and their families yet. In this study, factors affecting exposure to $\mathrm{CHE}$ analyzed in households of health staffs of a university of medical sciences in Iran.

\section{Methods}

This was a cross-sectional study. The study population consisted of all households of health staffs affiliated to army universities of medical sciences in Tehran. Data gathering from households was directly conducted through the survey method. 240 households were randomly selected from the health staffs of the university using stratified random sampling method.

In this study, the WHO questionnaire titled "World Health Survey" (6) which was designed in 2003 to assess the performance of health systems was used. This questionnaire is a valid, reliable, and comparative instrument developed by the World Health Organization for countries in order to monitor health system performance (6). Thus, for calculating CHE based on the WHO standard method -also applied in previous studies (7), first the capacity to pay was specified for each household, and then the proportion of health expenditure to paying capacity was calculated for them . Finally, according to the WHO standard definition, households who spent more or equal $40 \%$ capacity to pay for health expenditures were placed in the groups faced CHE (8).

Moreover, the WHO standard procedures were treated to identify households who have gone below the poverty line due to paying health expenditures. so that expenses the households have been driven below the poverty line due to health costs when the difference between the outof-pocket cost and the total household's spending be less than household's subsistence expenses (8). In other words, we subtracted the out of the pocket health costs from the total cost of households, then if the result is lower than the household's living expenses, indicates that the household has been driven out below the poverty line. Finally, the collected data were analyzed through descriptive statistics and chi-square test using SPSS20 software. Moreover, logistic regression model was used to analyse the odds ratios and determinants of exposure to $\mathrm{CHE}$.

\section{Results}

Sixty-seven percent of surveyed households had incomes above 30 million Riyals per year. About $94 \%$ of the heads of households were male, and the rest were female. Also, 87\% of households' heads had academic degrees. Mean Health expenditure of households and Mean total expenditure of households were $19904167 \pm 7129054$ and $2611958 \pm 3891482$, respectively. The socio-economic characteristics of surveyed households are presented in Table 1.

Moreover, the results showed that $7.5 \%$ of the surveyed households (18 households) had spent more than $40 \%$ of their ability to pay on health expenditures and were exposed to CHE. Furthermore, $11.3 \%$ of the households $(27$ households) had spent between 30 to $40 \%$ of their capacity to pay on medical expenses and were on the verge of facing CHE. Table 2 shows the proportion of the capacity to pay devoted to health expenditures.

The results of estimation logistic regression model are presented in Table 3. Based on the results of logistic regression, the odds ratio of exposing to $\mathrm{CHE}$ for some households were significantly more than others $(\mathrm{p}<0.05)$. Households who have using dental services during the past year were 8.77 times more at risk of CHE. Also, households with 3 members and less, households with lower education level and households with two or more outpatient visits were 8.59, 7.96 and 3.39 times more at risk of such payments respectively. No significant relationship was observed among other socio-economic characteristics (e.g., type of insurance, age, sex, etc.) and the odds of exposure to CHE. (goodness of fit measures; Hosmer and Lemeshow Test: Chi-square=3.217, $\mathrm{p}=0.864)$.

Moreover, the results also showed that $1.67 \%$ of all surveyed households (four families) were driven below the poverty line due to payment for medical expenditures. The relation between impoverishment health expenditures and CHE are presented in Table 4. The results of Table 4 showed that there is a significant statistical relationship between exposure to $\mathrm{CHE}$ and the poverty due to health care payments $(\mathrm{p} \leq 0.001)$ so that all households who driven below the poverty line were among households facing CHE. 


\begin{tabular}{|c|c|c|c|}
\hline Variables & & Number & Percentage \\
\hline \multirow[t]{2}{*}{ Income status } & $>30$ million Rials & 79 & $33 \%$ \\
\hline & $\leq 30$ million Rials & 161 & $67 \%$ \\
\hline \multirow[t]{2}{*}{ Age of household heads } & $>40$ years & 82 & $34 \%$ \\
\hline & $\leq 40$ years & 158 & $66 \%$ \\
\hline \multirow[t]{2}{*}{ Household size } & $1-3$ members & 127 & $53 \%$ \\
\hline & 4 members or more & 113 & $47 \%$ \\
\hline \multirow[t]{2}{*}{ Gender of household head } & Male & 226 & $94.2 \%$ \\
\hline & Female & 14 & $5.8 \%$ \\
\hline \multirow[t]{2}{*}{ Educational level of household head } & Not having university degrees & 31 & $12.9 \%$ \\
\hline & Having university degrees & 209 & $87.1 \%$ \\
\hline \multirow[t]{2}{*}{ Employment status of household head } & Private section & 35 & $14.6 \%$ \\
\hline & Public section & 205 & $85.4 \%$ \\
\hline \multirow[t]{2}{*}{ Insurance status of household head } & Health insurance organization & 130 & $54.2 \%$ \\
\hline & Social security Organization & 110 & $45.8 \%$ \\
\hline \multirow[t]{2}{*}{ Inpatient service usage } & Yes & 44 & $18.3 \%$ \\
\hline & No & 196 & $81.7 \%$ \\
\hline \multirow[t]{2}{*}{ Outpatient service usage } & Yes & 139 & $57.9 \%$ \\
\hline & No & 101 & $42.1 \%$ \\
\hline \multirow[t]{2}{*}{ Having under 5 years or over 65 in the family } & Yes & 46 & $19.2 \%$ \\
\hline & No & 194 & $80.8 \%$ \\
\hline \multirow[t]{2}{*}{ Dentistry usage } & Yes & 42 & $17.5 \%$ \\
\hline & No & 198 & $82.5 \%$ \\
\hline
\end{tabular}

Table 2. Quintiles of capacity to pay allocated to health expenditures by Households

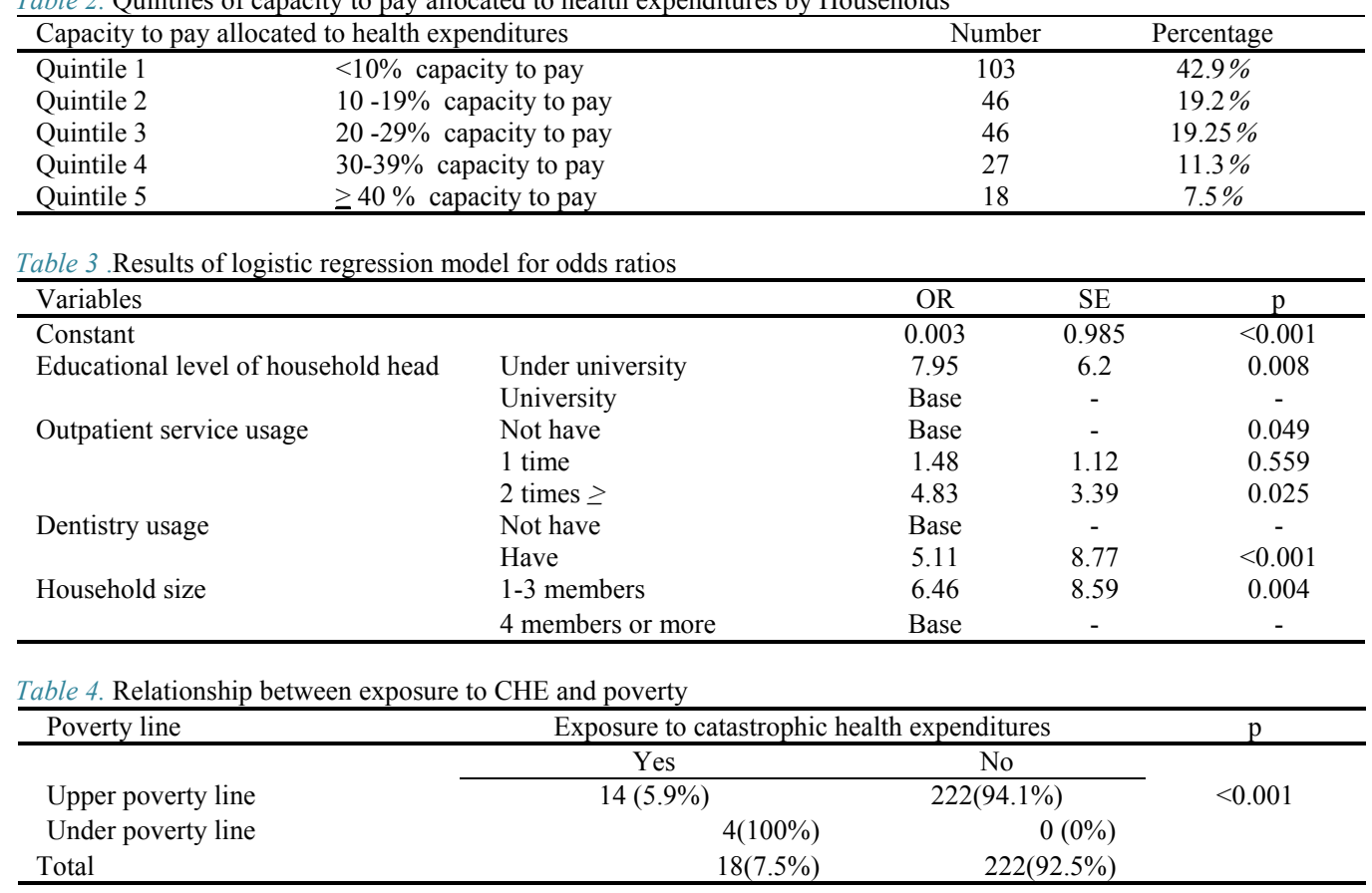

\section{Discussion}

The results show that exposure to catastrophic health costs in the studied households is higher than the national average and, of course, lower than studies conducted at the local level, thus increasing the coverage of insurance services and the quality of services covered to prevent the referral of the household to the private sector could be effective. According to our study results, $7.5 \%$ of health staff households have exposure to CHE. Also, $1.67 \%$ of them were driven below the poverty line due to payment for medical expenditures. Although these ratios are lower than the reported ratios in general population, still it's worrying. According to Kavoosi et al. study (7) carried out with a similar questionnaire in general households, exposure to $\mathrm{CHE}$ reported as $11.8 \%$ in 2007 . Also, Khammar- nia et al. study (9) reported that $7.1 \%$ of households have gone below the poverty line due to paying health expenditures in Shiraz province in 2012.

Moreover, the ratio of exposure to CHE in our study is higher than the reported ratios by studies which have used household budget data. The root cause of this difference is due to differences in measurement tool. Using proprietary tools developed specifically to verify the CHE can create different results compared to using tools designed for general-purposes (such as measuring the households' income-expenditure). In a study in Georgia in 2009, one of the causes of increasing the percentage of households facing CHE between 1999 (2.8\%) to 2007 (11.7\%) were attributed to the differences in data collection tool in two years (10). 
Although in our study, the proprietary tool designed by WHO for this purpose was used, but there are some studies conducted using national household budget data. The percentage of households facing CHE is underestimated in such studies. For example, Mehrara et al. study (11) showed that $6 \%$ of people had spent $30-40 \%$ of their capacity to pay for health expenditures in 2007. This rate is reported $2.79 \%$ by Yousefi et al. study in 2011 (12). On the other hand, Yusufi et al. study showed that $3.38 \%$ of households have suffered from the CHE and approximately $1.5 \%$ of them have fallen below the poverty line due to paying health expenditures in 2011. Razavi et al. study (13) showed that the proportion of households exposed to CHE was increased from $1.97 \%$ in 1997 to $2.32 \%$ in 2007 , which has had an increasing trend over time. One of the most important weaknesses of using household's budget to measure exposure to CHE is underestimation.

Based on our study results, nuclear families with more referring to health centers and less education level and also the dental services users are more likely to expose with CHE. Similarly, Zhang Hu et al. study (14) in elderly households in Chinese National Health Organization showed that the main factors associated with exposure to CHE are including household size, annual family income, having people over 65 years of age and presence of chronic illness. Also, according to Yang Jiang et al. study (15) in 2013, most of the inequalities observed in CHE were due to household size and economic status.

In addition, the lack of Health Insurance and coverage of elderly members were stated to be one of the important factors affecting CHE. Also, Loganathan et al. (16) in a study conducted on the CHE and poverty in Kuala Lumpur concluded that the lowest quintile of income compared to the highest quintile were more likely to expose CHE. In addition, Boeing et al. (17) studied the effect of socio-economical inequalities on $\mathrm{CHE}$ in Brazil and found that the CHE is mainly common among the poorest households and those headed by less educated persons.

Steven and Rima (18) in a study on the CHE and it's effective factors in the poor and populous areas of Kenya found that the number of elderly people working in a family and registered as members of a Social Security Network reduce the risk of exposure to catastrophic expenditures. Using public or private hospital cares increase the risk of exposure to catastrophic expenditures. Also, Lee et al. (19) found in their study that households who have a hospitalized member, elderly member, and members with a chronic disease or those living in rural areas are more exposed to $\mathrm{CHE}$.

However, similar to previous studies, the present study has limitations that we would like to note them as; Despite the technique (WHO approach) applied in this study to measure catastrophic expenditures which is one of the most common methods in calculating catastrophic expenditures throughout different countries, it should be noted that some limitation in data gathering may occur. The recall periods and the framing of the expenditure questions can affect estimations. Households may refuse giving accurate answers to the entire question or may refuse participating in the study.
Study Strengths was: Investigating the CHE among health staff and their families would let the audiences to have a better judgment about the current situation in Iran. Also, the current study used a regression-based analysis to identify the main determinants of the catastrophic health expenditure among health staffs in Iran.

\section{Conclusion}

The results show that CHE is a common dilemma even among health staffs. Although health staffs exposure to CHE is lower than the general population, still it's worrying. Nuclear families by more referring to health centers and fewer education levels and also dental services users are more at risk of CHE. Health policy-makers should pay more attention to such at-risk groups. Increasing coverage of outpatient services and especially the development of dental health insurance is recommended as effective strategies in order to reduce exposure to $\mathrm{CHE}$.

\section{Acknowledgments}

Thanks to guidance and advice from the ViceChancellor of Research and Technology (Clinical Research Development Unit of Baqiyatallah Hospital).

\section{Conflict of Interests}

The authors declare that they have no competing interests.

\section{References}

1. Knaul FM, Arreola-Ornelas H, Mendez-Carniado O, Bryson-Cahn C, Barofsky J, Maguire R, et al. Evidence is good for your health system: policy reform to remedy catastrophic and impoverishing health spending in Mexico. Lancet. Lancet. 2006 Nov 18;368(9549):1828-41

2. Xu K, Evans DB, Kawabata K, Zeramdini R, Klavus J, Murray CJ. Household catastrophic health expenditure: a multicountry analysis. Lancet. 2003;362(9378):111-7.

3. van Doorslaer E, O'Donnell O, Rannan-Eliya RP, Somanathan A, Adhikari SR, Garg CC, et al. Effect of payments for health care on poverty estimates in 11 countries in Asia: an analysis of household survey data. Lancet. 2006;368(9544):1357-64.

4. World Health Organization (2006) World Health Report 2006: Working together for Health.Geneva: WHO.

5. Management and Planning Organization. Law of the Fourth Economic, Social and Cultural Development Plan of Islamic Republic of Iran, 2005- 2009. Management and Planning Organization of Iran: Tehran, 2004.

6. World Health Survey. WHO. 2003. Geneva. Available from http://www.who.int/healthinfo/survey/en./

7. Kavosi Z, Rashidian A, Pourreza A, Majdzadeh R, Pourmalek F, Hosseinpour AR, et al. Inequality in household catastrophic health care expenditure in a low-income society of Iran. Health Policy Plan. 2012;27(7):613-23.

8. World Health Organization. The world health report 2000-health systems: improving performance: Geneva: World Health Organization; 2000.

9. Khammarnia M, Keshtkaran A, Kavosi Z, Hayati R. The Household Health Spending and Impoverishment: Findings from the Households Survey in Shiraz, Iran. Bangladesh Medical Research Council bulletin. 2014;40(2):58-62.

10. Gotsadze G, Zoidze A, Rukhadze N. Household catastrophic health expenditure :evidence from Georgia and its policy implications. BMC Health Serv Res. 2009;9:69.

11. Mehrara M, Fazaeli AA, Fazaeli AA. Health Finance Equity in Iran: an Analysis of Household Survey Data. J Health Administ. 2010;13(40):51-61.( Persian)

12. Yousefi M, Assari Arani A, Sahabi B, Kazemnejad A, Fazaeli S. 
The Financial Contribution Of Households Using By Health Services. Journal of payavard salamat. Feb 2015:517-527. (Persian)

13. Razavi M, Hasanzadeh A, Basmangi K. Fairness in Financial Contribution. Tehran: Ministry of Health and Medical Education. 2005;22. (Persian)

14. Wang Z, Li X, Chen M. Catastrophic health expenditures and its inequality in elderly households with chronic disease patients in China. Int J Equity Health. 2015;14:8.

15. Xu Y, Gao J, Zhou Z, Xue Q, Yang J, Luo H, et al. Measurement and explanation of socioeconomic inequality in catastrophic health care expenditure: evidence from the rural areas of Shaanxi Province. BMC Health Serv Res. 2015;15:256.

16. Loganathan T, Lee WS, Lee KF, Jit M, Ng CW. Household catastrophic healthcare expenditure and impoverishment due to rotavirus gastroenteritis requiring hospitalization in Malaysia. PloS One .(5)10, 2015:e 0125878.

17. Boing AC, Bertoldi AD, Barros AJ, Posenato LG, Peres KG. Socioeconomic inequality in catastrophic health expenditure in Brazil. Rev Saude Publ. 2014;48(4):632-41.

18. Buigut S, Ettarh R, Amendah DD. Catastrophic health expenditure and its determinants in Kenya slum communities. Int J Equity Health. 2015;14:46.

19. Li Y, Wu Q, Xu L, Legge D, Hao Y, Gao L, et al. Factors affecting catastrophic health expenditure and impoverishment from medical expenses in China: policy implications of universal health insurance. B World Health Organ. 2012;90(9):664-71. 